\title{
Cardio-Thoracic Ratio Evaluation of Cardiac Sihlouette Compared with the Vertebral Heart Scale in Cats
}

\author{
Oana BÎRSAN*, Andrei BAISAN, Diana MOCANU, Vasile VULPE \\ Department of Veterinary Medicine.University of Agricultural Sciences and Veterinay Medicine "Ion \\ Ionescu de la Brad", Iasi, Romania \\ *Corresponding author: oana_birsan1989@yahoo.com
}

Bulletin UASVM Veterinary Medicine 73(1) / 2016,

Print ISSN 1843-5270; Electronic ISSN 1843-5378

DOI:10.15835/buasvmcn-vm: 11404

\begin{abstract}
The aim of the study was to compare the VHS with CTR and to asses the discrimination potential of CTR between normal heart size and microcardia or cardiomegaly in cats. The study included 125 cats, 68 females and 57 males with age between 1 and 17 years. The patiens were distributed in 3 groups based on VHS: Group A ( $n=31$ ) cats with small cardiac size (microcardia), Group B ( $\mathrm{n}=51$ ) cats with normal cardiac size and Group C ( $=43$ ) cats with heart enlargement (cardiomegaly). There was a good correlation between VHS and CTR for the entire studied group $\left(r^{2}=0.516, p<0.01\right)$. There was a statistically significant correlation between VHS and CTR in normal heart size and cardiomegaly groups $\left(r^{2}=0.383 ; p<0.01\right),\left(r^{2}=0.339, p<0.05\right)$. There was a poor correlation between VHS and CTR in microcardia $\left(r^{2}=0.164 ; p=0.378\right)$.

There was statistically diference between microcardia group and normal cardiac size group $(p<0.05)$ and also between cardiomegaly and normal cardiac size groups $(p<0.01)$. Cardio-thoracic ratio is a valid method being well correlated with VHS. The CTR measurement can be used for assessing cardiac size in cats and can discriminate between normal heart size and microcardia or cardiomegaly.
\end{abstract}

Keywords: cat, cardiothoracic ratio, heart, vertebral heart scale, $x$-ray

\section{INTRODUCTION}

Thoracic radiography is an essential imagining method for assessing the cardiovascular and pulmonary modifications ( Rudorf et al., 2008). The heart is a muscular organ contrasting with the lung tissue surrounding it. (Johnsonet al., 2008)

Multiple methods have been developed in order to measure and quantify heart size in small animals and a variety methods are being used. (Johnson et al., 2008)

In 1995, Buchannan proposed a method for the cardiac size measurement in dogs, known as the vertebral heart scale (VHS) which is considered the most common and precise in veterinary medicine. It consists in scalning the dimenions of the long and short axis of the heart to the vertebral bodies, starting from the cranial aspect of $\mathrm{T} 4$, towards the lombar spinal column. The limits of the VHS for dogs were 9,7 $\pm 0,5$ vertebrae without major differences between breeds. (Buchanan and Bucheler 1995)

Later, in 2000, Lister and Buchannan performed a study on 100 clinically normal cats. The limits of VHS were 7,5 \pm 3 vertebrae. ( Lister and Buchanan 2000)

Recently, a new planar method, the cardiothoracic ratio (CTR), have been described, which measures the ratio between the heart and the thorax area. (Torad and Hassan 2014) From authors knowledge no study assesing the CTR value in cats have been described. 
The aim of the study was to compare the VHS with CTR and to asses the discrimination potential of CTR between normal heart size and microcardia or cardiomegaly in cats.

\section{MATERIALS AND METHODS}

The study included 125 cats, from different breeds, 68 females and 57 males with age between 1 and 17 years, referred to the Roentgendiagnostic Laboratory of the Faculty of Veterinary Medicine in Iasi, for thoracic X-ray examination, between January 2013 and December 2014. The breeds investigated were European breed $(n=88)$, Birmanese ( $n=88)$, Persian $(n=55)$, Siamese $(n=5)$, Angora ( $n=2)$, Russian Blue ( $n=1)$, Siberian $(n=1)$ and Scottishfold $(\mathrm{n}=1)$.

Thoracic X-ray examination have been performed in left or right lateral recumbency for all the patients. The X-rays were performed with the Intermedical Basic 4006 X-ray machine, developing process was performed automatically with the HQ-350XT developer machine. The parameters used for the exposure were between 44-47 Kv/1,3-1,6 mAs deppending on the animal body condition. The X-ray film were $13 / 24 \mathrm{~cm}$ and $24 / 30 \mathrm{~cm}$. Finally X-rays were scanned with the HP Scanjet G4050 scanner and transferred on a computer for measurement of the VHS and CTR.

The measurements were performed with Digimizer ${ }^{\circledR}$ softwere and included the VHS, the cardiac area (CA), the thoracic area (TA) and the CTR using the formula (AC*100/AC). The thoracic area (TA) and the cardiac area (AC) were assessed in pixels.

For the measurement of the thoracic area a line have been manually drawn from the point of the right crura of the lumbodiaphragmatic recess following the diaphragm cupola to the sternodiaphragmatic angle, then the dorsal aspect of the sternum, until the cranial edge of the first sternebra, the thoracic inlet, the ventral border of the thoracic vertebral bodies and back to the right crura of the lumbodiaphragmatic recess. For the

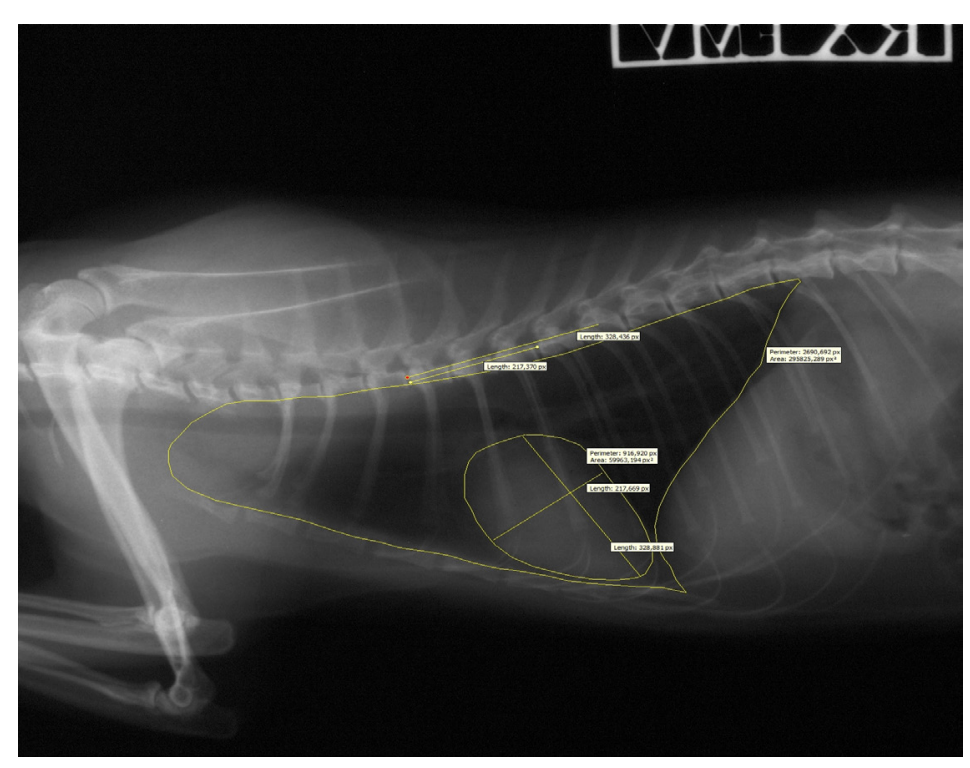

Fig. 1. Lateral thoracic radiography of a cat showing the measurement method of VHS and CTR .

Tab. 1. The mean and standard deviation of VHS and CTR for the three groups of cats

\begin{tabular}{cccc}
\hline Groups & $\begin{array}{c}\text { GroupA } \\
\text { (microcardia) }\end{array}$ & $\begin{array}{c}\text { Group B } \\
\text { (normal heart size) }\end{array}$ & $\begin{array}{c}\text { Group C } \\
\text { (cardiomegaly) }\end{array}$ \\
\hline Number of cats & 31 & 51 & 43 \\
\hline $\begin{array}{c}\text { Mean } \pm \text { SD } \\
\text { VHS }\end{array}$ & $6,92 \pm 0,22$ & $7,47 \pm 0,19$ & $8,35 \pm 0.50$ \\
\hline $\begin{array}{c}\text { Mean } \pm \text { SD } \\
\text { CTR }\end{array}$ & $18,48 \pm 1,94$ & $19,79 \pm 2,41$ & $21,75 \pm 3,42$ \\
\hline
\end{tabular}


cardiac area an outline have been traced to asses the cardiac sihlouette (Fig.1).

The patiens were distributed into 3 groups based on VHS value: Group A - microcardia $(n=31)$, cats with small cardiac size, Group B $(n=51)$ cats with normal cardiac size and Group C cardiomegaly $(n=43)$, cats with heart enlargement. The table below represents the mean and standard deviation for each group regarding the VHS and CTR values (Tab. 1).

\section{RESULTS AND DISCUTIONS}

Authors found a good, liniar, positive corelation $\left(r^{2}=0.516, p<0.01\right)$ between the two methods, VHS and CTR for the entire studied group (Graphic 1).

There was also a statistically significant correlation between VHS and CTR in normal heart size $\left(r^{2}=0.383 ; p<0.01\right)$ and cardiomegaly groups $\left(r^{2}=0.339, p<0.05\right)$. Between VHS and CTR in microcardia group no correlation was obtained $\left(r^{2}=0.164 ; p=0.378\right)$ (Tab. 2).

There was a statistically significant diference between microcardia group and normal cardiac size group $(p<0.05)$ and also between cardiomegaly and normal cardiac size groups $(p<0.01)$ using the CTR method (Tab 3).

Because VHS is considered the golden standard for cardiac silhouette measurement for dogs and cats on X-ray, the groups distribution was based on this method and the CTR was used to assess the cardiac size. Furthermore, using the VHS method as reference, the authors assessed the discrimination potential between groups using the CTR meaurement. The thorax and the heart of the cats have a similar conformation and the size and shape varies lesser than dogs (Johnson et al., 2008), reducing the bias of the measurement ratio. The cardiothoracic ratio is a new method using

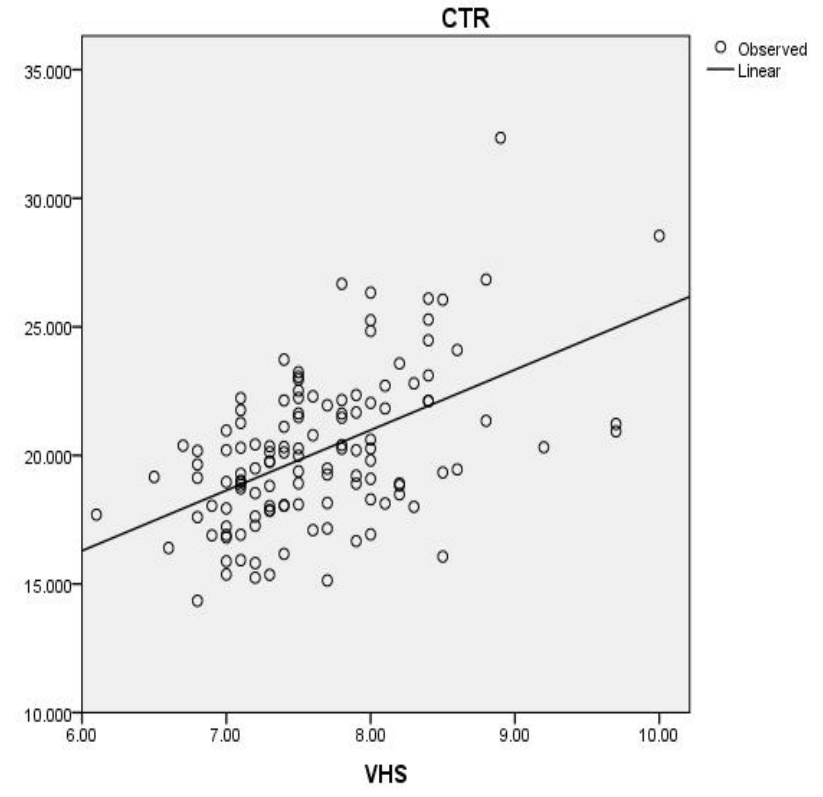

Graphic 1 Scatterplot showing the correlation between vertebral heart scale and cardio thoracic ratio for the entire studied group.

Tab. 2. Correlation between VHS and CTR among groups distributed by cardiac size using the VHS method.

\begin{tabular}{ccc}
\hline Groups & $\boldsymbol{R}^{2}$ & $\boldsymbol{p}$ \\
\hline Microcardia & 0.164 & 0.378 \\
\hline Normal cardiac size & 0.383 & $p<0.01$ \\
\hline Cardiomegaly & 0.339 & $p<0.05$ \\
\hline
\end{tabular}

Tab. 3. Statistic diference groups based on CTR measurement

\begin{tabular}{cc}
\hline CTR & P \\
\hline Microcardia - Normal cardiac size & $p<0.05$ \\
\hline Cardiomegaly- Normal cardiac size & $p<0.01$ \\
\hline
\end{tabular}


plannar measurement instead of linear ones, the latter excluding some areas from the heart such as left atrium dilatation.

For a better reliability of the method, it would have been recommanded the use of more specific measurements, such as ultrasonographic examination for diagnosing certain pathologies such as atrial enlargement wich is very common in cats with hypertrophic cardiomyopathy (Fox, 2003).

\section{CONCLUSIONS}

Cardio-thoracic ratio is a valid method being well correlated with VHS. The CTR measurement can be used for assessing cardiac size in cats and can discriminate between normal heart size and microcardia or cardiomegaly.

The CTR measuring methods can determine the difference between normal cardiac silhouette and the enlarged one, therefore having a role in the diagnosis of cardiac disease (eccentric myocardial hypertrophy, atrial dilatation, or pericardial effusion).

\section{REFERENCES}

1. Buchanan JW, Bucheler J (1995). Vertebral scale to measure canine heart size in radiographs. J Am Vet Med Assoc 206:194-199.

2. Fox PR (2003). Hypertrophic Cardiomyopathy. Clinical and Pathologic Correlates. J Vet Cardiol 5(2):39-45.

3. Johnson V, Hansson K, Mai W et al (2008). The heart and major vassels. In: Schwarz T, Johnson V (Eds.) BSAVA manual of canine and feline thoracic imaging, BSAVA, 86176.

4. Lister AL, Buchanan JW (2000). Vertebral scale system to measure heart size in radiographs of cats. J Am Vet Med Assoc 15;216(2):210-4.

5. Rudorf H, Taeymans O, Johnson V (2008). Basics of thoracic radiography and radiology. In: Schwarz T, Johnson V ( Eds.). BSAVA manual of canine and feline thoracic imaging, BSAVA, 1-20.

6. Torad FA, Hassan EA (2014). Two-dimensional cardiothoracic ratio for evaluation of cardiac size in German shepherd dogs. J Vet Cardiol 16:237-244. 